\title{
Bafilomycin $\mathrm{K}$, a new antifungal macrolide from Streptomyces flavotricini Y12-26
}

\author{
Dao-jing Zhang ${ }^{1}$, Gang $\mathrm{Wei}^{2}$, Ying Wang ${ }^{2}$, Cong-cong $\mathrm{Si}^{2}$, Li Tian ${ }^{3}$, Li-ming $\mathrm{Tao}^{2}$ and Yuan-guang $\mathrm{Li}^{1}$
}

The Journal of Antibiotics (2011) 64, 391-393; doi:10.1038/ja.2011.12; published online 9 March 2011

Keywords: antifungal activity; bafilomycin K; macrolide; Streptomyces flavotricini

Because of the special living environment, marine-derived actinomycetes, especially the genus Streptomyces, possess distinct and complex metabolic capabilities, resulting in wide diversity of their secondary metabolites in chemical structures and biological activities. ${ }^{1}$ Among them, many valuable lead compounds were obtained for discovery of new antibiotics. ${ }^{2-4}$ Bafilomycins are a family of polyene macrolides containing a 16-member lactone ring. Thirteen bafilomycin antibiotics have been isolated, including bafilomycins $A_{1}, A_{2}, B_{1}, B_{2}, C_{1}$ and $C_{2}$ from Streptomyces griseus sp. sulphurus (TU 1922), ${ }^{5}$ bafilomycins D and E from S. griseus TU $2599^{6}$ and bafilomycins F-J from Streptomyces spp. ${ }^{7}$ Among them, bafilomycins $\mathrm{D}$ and $\mathrm{E}$ contain the ringopened side chain different from other bafilomycins. Bafilomycins have antibacterial, antifungal, antineoplastic and immunosuppressive activities. ${ }^{5}$ Some bafilomycins are specific inhibitors of vacuolar-type $\mathrm{H}^{+}$-ATPase (V-ATPase), ${ }^{8-11}$ in which bafilomycin $\mathrm{A}_{1}$ is the most used. Being a specific inhibitor of V-ATPase, bafilomycin $A_{1}$ can prevent the re-acidification of synaptic vesicles once they have undergone exocytosis. In addition, bafilomycin $\mathrm{A}_{1}$ has antimalarial activity. ${ }^{12}$ Bafilomycins $B_{1}$ and $C_{1}$ have been mentioned as potential antiosteoporotic agents in treating bone lytic diseases.

In order to obtain new antibiotics from marine-derived actinomycetes, we screened the antifungal substances produced by S. flavotricini Y12-26 isolated from mangrove plant Acanthus ilicifolius grown in the intertidal zone of the Hainan province of China. We first found that the culture broth of S. flavotricini Y12-26 showed strong antifungal activity against Pyricularia oryzae, and a new antifungal macrolide named bafilomycin K (1, Figure 1) was then isolated from the fermentation broth of this strain. Its structure was established to be a new member of bafilomycins with a 16-member lactone ring by spectroscopic analysis. This paper describes the isolation, structure elucidation and antifungal bioassay of $\mathbf{1}$.

The marine actinomycetes Y12-26, isolated from mangrove plant A. ilicifolius grown in the intertidal zone of the Hainan province of China, was identified as Streptomyces flavotricini according to its morphological characters, biochemical characters and the partial sequence of its $16 \mathrm{~S}$ rDNA. The strain was deposited in China General Microbiological Culture Collection Center, Beijing, China (CGMCC No. 3832).

The culture broth of $S$. flavotricini Y12-26 was conducted in shake flasks. The germination medium contained glucose $20.0 \mathrm{~g}$, soybean grits $25.0 \mathrm{~g}$, starch $10.0 \mathrm{~g}$, yeast powder $4.0 \mathrm{~g}, \mathrm{NaCl} 20.0 \mathrm{~g}$, beef extract $1.0 \mathrm{~g}$ and $\mathrm{K}_{2} \mathrm{HPO}_{4} 50.0 \mathrm{mg}$ in $1.01 \mathrm{lof}$ tap water with $\mathrm{pH} 7.2$. Each $250 \mathrm{ml}$ flask containing $70 \mathrm{ml}$ of this medium was incubated with $2 \mathrm{ml}$ of the stock culture. The flasks were incubated at $28^{\circ} \mathrm{C}$ on a rotary shaker at 220 r.p.m. for 12 days. Culture broth (301) of S. flavotricini Y12-26 was centrifuged at 4000 r.p.m. for $10 \mathrm{~min}$ to get the mycelia. The mycelia were then extracted three times with $80 \%$ acetone. The $80 \%$ acetone extracts were then concentrated in vacuo to afford residue, which was then extracted with $n$ - $\mathrm{BuOH}$ three times. The $n$ - $\mathrm{BuOH}$ extracts were further extracted with $\mathrm{MeOH}$. The $\mathrm{MeOH}$ extract was then subjected to silica gel column eluted with $\mathrm{CH}_{2} \mathrm{Cl}_{2}-$ $\mathrm{MeOH}$ system (60:1 v/v) to get the active component Y12-26-A, and the active fraction of Y12-26-A was further purified by pre-TLC eluted with $\mathrm{CH}_{2} \mathrm{Cl}_{2}-\mathrm{MeOH}(40: 1 \mathrm{v} / \mathrm{v})$ to get active component with $\mathrm{R}_{\mathrm{f}}=0.35$, and finally purified by HPLC (Nucleosil C18 (Macherey-Nagel, Düren, Germany), $5 \mu \mathrm{m}, 30 \times 250 \mathrm{~mm}, 16 \mathrm{ml} \mathrm{min}^{-1}$, UV detection $247 \mathrm{~nm}$ ) eluted with $\mathrm{CH}_{3} \mathrm{OH}-\mathrm{MeCN}-\mathrm{H}_{2} \mathrm{O}(40: 38: 22, \mathrm{v} / \mathrm{v} / \mathrm{v})$ to yield $1(9.6 \mathrm{mg}$, retention time $=63 \mathrm{~min}$ ).

Compound 1 was obtained as colorless amorphous powder (UV $(\mathrm{MeOH}) \lambda_{\max } 247.2 \mathrm{~nm}$ and $278.4 \mathrm{~nm}$ ) by a multi-step chromatography procedure from the culture broth of the S. flavotricini Y12-26. It gave an $[\mathrm{M}+\mathrm{Na}]^{+}$peak in the high-resolution electrospray-ionization MS (HR-ESI-MS) at $\mathrm{m} / z 629.3929$ (Calcd for $\mathrm{C}_{35} \mathrm{H}_{58} \mathrm{O}_{8} \mathrm{Na}$, 629.4024). The ${ }^{13} \mathrm{C}$ NMR spectrum of 1 (Table 1) attributable to one ester carbonyl $\left(\delta_{\mathrm{C}} 172.0\right)$ and eight olefinic carbons $\left(\delta_{\mathrm{C}} 122.3\right.$, $146.5,134.5,144.6,142.7,125.3,132.5,127.5)$, accounted for seven of the degrees of unsaturation, suggesting that 1 is bicyclic. The ${ }^{1} \mathrm{H}$ NMR spectrum (Table 1) showed signals for 10 methyl groups at $\delta_{\mathrm{H}}(2.05$,

${ }^{1}$ State Key Laboratory of Bioreactor Engineering, East China University of Science and Technology, Shanghai, PR China; ${ }^{2}$ Shanghai Key Lab of Chemical Biology, Pharmaceutical College, East China University of Science and Technology, Shanghai, PR China and ${ }^{3}$ First Institute of Oceanography, State Oceanic Administration, Qingdao, PR China Correspondence: Professor L-m Tao, Shanghai Key Lab of Chemical Biology, Pharmaceutical College, East China University of Science and Technology, Meilong road 130, Shanghai 200237, PR China.

E-mail: taolm@sh163.net

Received 11 October 2010; revised 15 January 2011; accepted 22 January 2011; published online 9 March 2011 
<smiles>COC1/C=C/C=C(\C)CC(C)C(O)C(C)/C=C(C)/C=C(/C)C(=O)OC1C(C)C(O)C(C)C1(O)CC(O)C(C)C(C(C)C)O1</smiles>

Figure 1 Structure of 1.

Table $1{ }^{1} \mathrm{H}(400 \mathrm{MHz})$ and ${ }^{13} \mathrm{C}(100 \mathrm{MHz}) \mathrm{NMR}$ data for 1 in $\mathrm{CDCl}_{3}$

\begin{tabular}{|c|c|c|}
\hline Position & $\delta_{C}$ & $\delta \mathrm{H}(\mathrm{J}$ in $\mathrm{Hz})$ \\
\hline 1 & 172.0 & \\
\hline 2 & 122.3 & \\
\hline 3 & 146.5 & $7.24(1 \mathrm{H}, \mathrm{s})$ \\
\hline 4 & 134.5 & \\
\hline 5 & 144.6 & $5.85(1 \mathrm{H}, \mathrm{s})$ \\
\hline 6 & 36.7 & $2.57(1 \mathrm{H}, \mathrm{m})$ \\
\hline 7 & 81.3 & $3.32(1 \mathrm{H}, \mathrm{s})$ \\
\hline $7-\mathrm{OH}$ & & $1.59(1 \mathrm{H}, \mathrm{d}, \mathrm{J}=6.5)$ \\
\hline 8 & 39.8 & $1.95(1 \mathrm{H}, \mathrm{s})$ \\
\hline 9 & 41.2 & $2.17(1 \mathrm{H}, \mathrm{m}), 1.95(1 \mathrm{H}, \mathrm{s})$ \\
\hline 10 & 142.7 & \\
\hline 11 & 125.3 & $5.88(1 \mathrm{H}, \mathrm{s})$ \\
\hline 12 & 132.5 & $6.52(1 \mathrm{H}, \mathrm{dd}, J=14.8,10.8)$ \\
\hline 13 & 127.5 & $5.21(1 \mathrm{H}, \mathrm{dd}, J=14.8,9.6)$ \\
\hline 14 & 82.6 & $3.93(1 \mathrm{H}, \mathrm{t}, \mathrm{J}=8.8)$ \\
\hline 14-OMe & 55.6 & $3.27(3 \mathrm{H}, \mathrm{s})$ \\
\hline 15 & 76.0 & $4.98(1 \mathrm{H}, \mathrm{d}, J=8.1)$ \\
\hline 16 & 37.6 & $2.10(1 \mathrm{H}, \mathrm{m})$ \\
\hline 17 & 70.4 & $4.11(1 \mathrm{H}, \mathrm{d}, J=10.5)$ \\
\hline $17-\mathrm{OH}$ & & $4.86(1 \mathrm{H}, \mathrm{s})$ \\
\hline 18 & 41.8 & $1.76(1 \mathrm{H}, \mathrm{d}, J=7.2)$ \\
\hline 19 & 98.9 & \\
\hline 19-OH & & $5.64(1 \mathrm{H}, \mathrm{s})$ \\
\hline 20 & 43.4 & $2.30(1 \mathrm{H}, \mathrm{dd}, J=12.0,4.1), 1.15(1 \mathrm{H}, \mathrm{s})$ \\
\hline 21 & 71.0 & $3.70(1 \mathrm{H}, \mathrm{m})$ \\
\hline 22 & 41.1 & $1.33(1 \mathrm{H}, \mathrm{m})$ \\
\hline 23 & 75.7 & $3.50(1 \mathrm{H}, \mathrm{d}, J=10.1)$ \\
\hline 24 & 27.9 & $1.90(1 \mathrm{H}, \mathrm{m})$ \\
\hline 25 & 14.4 & $0.78(3 \mathrm{H}, \mathrm{d}, J=6.6)$ \\
\hline 26 & 13.7 & $2.05(3 \mathrm{H}, \mathrm{s})$ \\
\hline 27 & 15.2 & $2.00(3 \mathrm{H}, \mathrm{s})$ \\
\hline 28 & 17.5 & $1.10(3 \mathrm{H}, \mathrm{d}, J=6.8)$ \\
\hline 29 & 21.5 & $0.96(3 \mathrm{H}, \mathrm{d}, J=5.6)$ \\
\hline 30 & 20.1 & $1.95(3 \mathrm{H}, \mathrm{s})$ \\
\hline 31 & 9.8 & $0.83(3 \mathrm{H}, \mathrm{d}, J=6.7)$ \\
\hline 32 & 6.9 & $1.05(3 \mathrm{H}, \mathrm{d}, J=7.0)$ \\
\hline 33 & 12.1 & $0.96(3 \mathrm{H}, \mathrm{d}, J=5.6)$ \\
\hline 34 & 20.8 & $0.92(3 \mathrm{H}, \mathrm{d}, J=6.7)$ \\
\hline
\end{tabular}

2.00, 1.95, 1.10, 1.05, 0.96, 0.96, 0.92, 0.83, 0.78, 3H each) and one methoxy group at $\delta_{\mathrm{H}}(3.27,3 \mathrm{H})$. The ${ }^{13} \mathrm{C}$ NMR spectrum also showed the presence of 10 methyl groups at $\delta_{\mathrm{C}}(21.5,20.8,20.1,17.5,15.2$, $14.4,13.7,12.1,9.8,6.9)$ and one methoxy group at $\delta_{\mathrm{C}} 55.6$. These data also pointed to a bafilomycin derivative skeleton. The structure of 1 (Figure 1) was further elucidated by 2D-NMR analyses including HMQC, ${ }^{1} \mathrm{H}-{ }^{1} \mathrm{H}$ COSY and HMBC experiments (Figure 2). Finally, 1

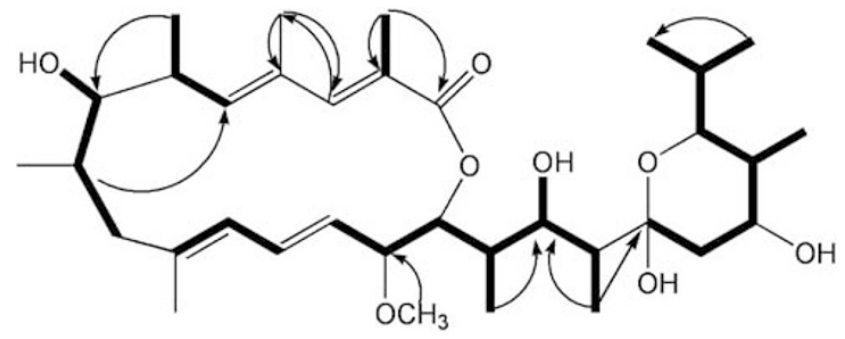

Figure 2 COSY (bold lines) and HMBC (arrows) correlations of $\mathbf{1}$.

Table 2 MIC value for phytopathogens of 1

\begin{tabular}{lrrr}
\hline & \multicolumn{3}{c}{ MIC $\left(\mu \mathrm{g} \mathrm{m{ } ^ { - 1 } )}\right.$} \\
\cline { 2 - 4 } Plant pathogens & 1 & Bafilomycin $A_{1}$ & Bafilomycin D \\
\hline Pyricularia oryzae & 31 & 16 & 125 \\
Botriytis cinerea & 250 & 125 & $>500$ \\
Rhizoctonia solani & 500 & 250 & $>500$ \\
Collectotrichum lagenarium & 62 & 125 & 250 \\
Helminthosporium maydis & 500 & 250 & $>500$ \\
Gibberella zeae & $>500$ & NT & NT \\
\hline
\end{tabular}

Abbreviation: NT, not tested.

Bafilomycins $A_{1}$ ( $\left.>95.0 \%, \mathrm{HPLC}\right)$ and $\mathrm{D}(>99.0 \%, \mathrm{HPLC})$ were both isolated from Streptomyces flavotricini Y12-26.

was established to be a new tetraene macrolide containing a 16-member lactone ring. The structure of 1 was nearly identical to that of bafilomycin J. ${ }^{7}$ The only difference between bafilomycin J and $\mathbf{1}$ was that the methyl ether at C-21 in bafilomycin J (21-OCH3) was replaced by a hydroxy group in $\mathbf{1}(21-\mathrm{OH})$, accounting for the different numbers of methyl in their formulas.

The three olefins at C-2,C-4 and C-12 were all determined to be E-configuration on the basis of their high-field ${ }^{13} \mathrm{C}$ chemical shifts of the methyl residues $2-\mathrm{CH}_{3}\left(\delta_{\mathrm{C}} 13.7\right)$ and $4-\mathrm{CH}_{3}\left(\delta_{\mathrm{C}} 15.2\right)$ and the coupling constants between $12-\mathrm{H} / 13-\mathrm{H}\left(J_{12-\mathrm{H}-13-\mathrm{H}}, 14.8\right)$. Another olefin at $\mathrm{C}-10$ also possessed $E$-configuration when ${ }^{13} \mathrm{C}$ chemical shifts at $10-\mathrm{CH}_{3}\left(\delta_{\mathrm{C}} 21.5\right)$ were compared with those of known analogs. ${ }^{7,10}$ The relative configuration of $\mathbf{1}$ may be deduced by comparison of the coupling constant with bafilomycin $\mathrm{A}_{1},{ }^{13}$ but further assignments will be supported by NOESY correlations and X-ray diffraction analysis.

The antifungal activities of $\mathbf{1}$, bafilomycins $A_{1}$ and $D$ against plant pathogens were determined by the serial two-fold agar dilution method. ${ }^{14}$ As shown in Table 2, the antifungal activities of 1 and bafilomycin $A_{1}$ with a bicyclic structure seem stronger than that of bafilomycin $\mathrm{D}$ containing the ring-opened side chain. Compound $\mathbf{1}$ showed medium activities against $P$. oryzae and Collectotrichum lagenarium with MICs of 31 and $62 \mu \mathrm{g} \mathrm{ml}^{-1}$, respectively. It showed low activities against Botriytis cinerea and Helminthosporium maydis with MICs of not less than $250 \mu \mathrm{g} \mathrm{ml}^{-1}$. However, it did not show antifungal activities against Rhizoctonia solani and Gibberella zeae at a concentration of $500 \mu \mathrm{g} \mathrm{ml}^{-1}$.

Bafilomycin $A_{1}, B_{1}$ and $C_{1}$ possess a broad activity spectrum, including fungi, Gram-positive bacteria and yeasts at a concentration of $1 \mathrm{mg} \mathrm{ml}^{-1}$. The antifungal activity of these three bafilomycins is more pronounced than the antibacterial effects by the disk-diffusion assay. ${ }^{5}$ Compound 1 and the three bafilomycins all exhibited antagonistic activity against $B$. cinerea, ${ }^{5}$ and bafilomycin $A_{1}$ also exhibited antagonistic activity against $B$. cinerea and $R$. solani in our research. However, compound 1 exhibited antifungal activities against plant 
pathogens at different concentrations. Therefore, these bafilomycins may have a role in the biocontrol of different plant pathogens. S. flavotricini strain Y12-26 could possibly be used as a bafilomycin producer for regulating plant disease.

\section{ACKNOWLEDGEMENTS}

This work was financially supported by the High-Tech Program (863 Program) of China (2008AA09Z407) and National Basic Research Program (973 Program) of China (2010CB126100).

1 Fiedler, H. P. et al. Marine actinomycetes as a source of novel secondary metabolites. Antonie van Leeuwenhoek. 87, 37-42 (2005).

2 Maskey, R. P. et al. Anti-cancer and antibacterial trioxacarcins with high anti-malaria activity from a marine streptomycete and their absolute stereochemistry. J. Antibiot. 57, 771-779 (2004).

3 Gorajana, A. et al. 1-hydroxy-1-norresistomycin, a new cytotoxic compound from a marine actinomycete, Streptomyces chibaensis AUBN(1)/7. J. Antibiot. 58, 526-531 (2005).

4 Kock, I., Maskey, R. P., Biabani, M. A., Helmke, E. \& Laatsch, H. 1-hydroxy-1norresistomycin and resistoflavin methyl ether: New antibiotics from marine derived streptomycetes. J. Antibiot. 58, 530-535 (2005).
5 Werner, G., Hagenmaier, H., Drautz, H., Baumgartner, A. \& Zähner, H. Metabolic products of microorganisms. 224. Bafilomycins, a new group of macrolide antibiotics. Production, isolation, chemical structure and biological activity. J. Antibiot. 37, 110-117 (1984).

6 Kretschmer, A., Dorgerloh, M., Deeg, M. \& Hagenmaier, H. The structures of novel insecticidal macrolides bafilomycins D and E, and oxohygrolidin. Agric. Biol. Chem. 49, 2509-2511 (1985).

7 Carr, G. et al. Bafilomycins produced in culture by Streptomyces spp. isolated from marine habitats are potent inhibitors of autophagy. J. Nat. Prod. 73, 422-427 (2010).

8 Bowman, E. J., Siebers, A. \& Altendorf, K. Bafilomycins: a class of inhibitors of membrane ATPases from microorganisms, animal cells, and plant cells. Proc. Nat Acad. Sci. USA. 85, 7972-7976 (1988).

9 Drose, S. et al. Inhibitory effect of modified bafilomycins and concanamycins on P- and V-type adenosinetriphosphatases. Biochem. 32, 3902-3906 (1993).

10 Ueda, J. Y., Hashimoto, J., Yamamura, H., Hayakawa, M., Takagi, M. \& Shin-ya, K. A new 16-membered tetraene macrolide JBIR-100 from a newly identified Streptomyces species. J. Antibiot. 63, 627-629 (2010).

11 Wang, Y. R., Inoue, T. \& Forgac, M. Subunit a of the yeast V-ATPase participates in binding of bafilomycin[J]. J. Biol. Chem. 280, 40481-40488 (2005).

12 van Schalkwyk, D. A. et al. Inhibition of plasmodium falciparum $\mathrm{pH}$ regulation by smal molecule indole derivatives results in rapid parasite death. Biochem. Pharmacol. 79, 1291-1299 (2010).

13 Baker, G. H., Brown, P. J., Dorgan, R. J. J. \& Everett, J. R. The conformational analysis of bafilomycin $A_{1}$. J. Chem. Soc., Perkin Trans. 2, 1073-1079 (1989).

14 Zhang, D. J., Liu, R. F., Li, Y. G., Tao, L. M. \& Tian, L. Two new antifungal cyclic lipopeptides from Bacillus marinus B-9987. Chem. Pharm. Bull. 58, 1630-1634 (2010) 